\title{
Pulmonary function in children with atrial septal defect before and after heart surgery
}

\author{
J Šulc, V Andrle, J Hruda, B Hučín, M Šamánek, A Zapletal
}

\begin{abstract}
Objective-To test the effect of heart disease and heart surgery on lung function.

Design-A pulmonary function study of children undergoing surgery for atrial septal defect (ASD).

Settings-University hospital.

Patients-26 children tested before surgery (at mean (SD) age 11.8 (3.8) years) and 24 patients tested $1.8(0.2)$ years after surgical correction.

Methods-Lung volumes, lung elasticity, and airway patency indices were measured using standard techniques.

Results-Before surgery: pulmonary function test abnormalities were found in $\mathbf{1 8}$ of the 26 patients. Stiff lung was found in 12 , lung hyperinflation in five, and indices of decreased airway patency in four. Total lung capacity decreased in only two patients. After surgery: pulmonary function test abnormalities were found in 12 of the 24 patients (informed consent not given for two patients). Stiff lung was detected in nine and indices of peripheral airway obstruction in four. Mean values of specific airway conductance and peak expiratory flow were all normal. Lung hyperinflation was found only in one of 24 patients. No correlation between perioperative events and pulmonary function test data was found.
\end{abstract}

Conclusions-Pulmonary function test abnormalities persist in half the patients almost two years after surgery for ASD. A decrease in the total frequency of pulmonary function test abnormalities (in $19 \%$ of the patients), with a decrease in stiff lung in $8 \%$ and lung hyperinflation in $15 \%$, was not significant. Impairment of lung function related to ASD is associated with the disease itself rather than the surgical procedure.

(Heart 1998;80:484-488)

Keywords: atrial septal defect; heart surgery; pulmonary function; cardiopulmonary development

Lung function abnormalities in patients with atrial septal defect (ASD) have been reported in adults and adolescents ${ }^{1-10}$ as well as in children and infants. ${ }^{11-17}$ The most prominent abnormalities are lung volume restriction ${ }^{1-5}$ and changes in residual volume and functional residual capacity. ${ }^{256}$ Normal $^{378}$ or decreased airway patency ${ }^{256}$ is found. Non-uniform changes in lung elasticity also occur. ${ }^{24} 6{ }^{9-14} 18-21$ Except in a study on adults, ${ }^{3}$ none of these

Abbreviations used for pulmonary
function tests
Cst/TLC, static compliance corrected for
total lung capacity
FRC, functional residual capacity
Gaw, airway conductance
IC, inspiratory capacity
MEF/TLC, maximum expiratory flow cor-
rected for total lung capacity
PEFR, peak expiratory flow
Pst, static lung recoil pressure
Raw, airway flow resistance
RV, residual volume
sGaw, specific airway resistance
TLC, total lung capacity
VC, vital capacity

studies has compared pulmonary function tests both before and a long time after heart surgery. Studies comparing lung function using a wide range of pulmonary function tests in children before and after surgery for ASD have not been reported. Our aim in this study was therefore to define the spectrum of pulmonary function test abnormalities in children and adolescents with ASD before heart surgery and over one year after correction.

\section{Methods}

\section{PATIENTS AND SURGICAL PROCEDURES}

Lung function was studied in 26 children (12 male, 14 female) before surgery for ASD (secundum type) and in 24 children after the surgery (informed consent was not obtained for the remaining two children). Apart from mild valvar pulmonary stenosis in two patients, no additional heart defects were present. Three patients had a history of repeated bronchitis or pneumonia. One patient was born during the 37 th week of gestation weighing $1900 \mathrm{~g}$. All the children were in excellent clinical condition at the time of the study (New York Heart Association class I). Informed consent was given on behalf of all the children.

Pulmonary function tests were done one to three days before surgery, which was performed at mean (SD) age 11.8 (3.8) years (median 12 years). The tests were repeated 1.79 (0.21) years later (median 1.8 years); at this time, mean height was $149.5(20.1) \mathrm{cm}$ and the patients were 14.0 (3.9) years old (median 14.8 years).

Left to right shunting before surgery was measured by radionuclide dilution in 25 of 26 patients and ranged between $14 \%$ and $67 \%$ of pulmonary blood flow (mean 45.2 (11.9)\%).

At surgery, the ASD was closed either by direct suture or by a pericardial patch using 
cardiopulmonary bypass, through a midline sternotomy. The duration of bypass was 31.0 (11.1) minutes (range 15 to 65 minutes), and an aortic cross clamp was in place for 12.7 (9.5) minutes (range 0 to 40 minutes). Almost all patients were extubated in the theatre; therefore the duration of postoperative mechanical ventilatory support was only 1.3 (1.9) hours, range 0 to 7 hours.

The early postoperative course was uneventful in the majority of the patients. One was reintubated and ventilated for six hours because of acute respiratory insufficiency and pneumopericardium during the first postoperative day. Three other patients developed a postpericardiotomy syndrome, atelectasis of the right middle lobe, and pneumopericardium, respectively. All these perioperative events recovered completely.

LUNG FUNCTION TESTS

Functional residual capacity was measured at end expiration as thoracic gas volume (TGV) in a body plethysmograph. Static lung volumes were derived from the measurements of TGV and from lung volumes calculated from the expiratory pressure-volume curve (see below). The highest vital capacity (VC) and inspiratory capacity (IC) values, taken as representative values in a particular subject, were used for the calculations. Total lung capacity (TLC) was obtained from the TGV plus IC, and the residual volume (RV) was calculated as TLC minus VC.

Lung elasticity was assessed from the expiratory pressure-volume curves obtained as a simultaneous recording of transpulmonary pressure (measured as the difference between oesophageal and mouth pressures) and lung volume changes. A latex oesophageal balloon (wall thickness up to $0.1 \mathrm{~mm}$, length $100 \mathrm{~mm}$ ) was situated in the lower third of the oesophagus. The pressure-volume curves were recorded under quasi-static conditions during very slow expiration, with airflow being interrupted by shutter valve for 0.3 seconds. At least five technically good pressure-volume curves were obtained from each patient. Lung recoil pressure was measured from the pressurevolume curves at $100 \%, 90 \%$, and $60 \%$ of TLC. Static lung compliance (Cst), another index of lung elasticity, was obtained from the slope of the middle linear part of pressurevolume curve. Expressed per unit of TLC, Cst gave a value for "specific" lung compliance (Cst/TLC).

Airway resistance (Raw) was measured during quiet breathing simultaneously with TGV in a body plethysmograph. Raw was converted to its inverse value (that is, airway conductance) and expressed per unit of TGV as specific airway conductance (sGaw). Maximum expiratory flow-volume curves were obtained by performing a complete and rapid expiration to residual volume level immediately after maximum inspiration. At least five technically good curves were recorded, from which we derived an "envelope" curve representative of each subject. Maximum expiratory flow-volume curves were used for the assessment of forced vital capacity (FVC), peak expiratory flow rate (PEF), maximum expiratory flow rates at $25 \%$ and $50 \%$ of forced vital capacity $\left(\mathrm{MEF}_{25} \mathrm{VC}, \mathrm{MEF}_{50} \mathrm{VC}\right)$, and at $60 \%$ of total lung capacity $\left(\mathrm{MEF}_{60} \mathrm{TLC}\right)$. In order to correct the absolute values of flow rates (litre/s) for lung size, ratios of maximum expiratory flow rates and TLC were calculated.

The results of pulmonary function test measurements are expressed as mean (SD) and as percentage of the predicted values. As reference values, we used pulmonary function test indices from a healthy population matched for height, sex, and age and measured using the same methods in the same laboratory. ${ }^{22}$ To compare preoperative and postoperative data, we calculated predicted values in both testing sessions.

\section{STATISTICS}

Differences between the parametric data were tested by Student's paired $t$ test where possible or by the unpaired $t$ test. Non-parametric data were compared by the Mann-Whitney test. The level of statistical significance was set at $p=0.05$. We examined the correlation between pulmonary function tests and preoperative data (magnitude of the left to right shunt), perioperative data (duration of cardiopulmonary bypass, duration of aortic cross clamp), and postoperative data (duration of ventilation, interval between surgery and testing). The correlation between the data was tested by the Pearson product moment correlation test.

\section{Results}

PULMONARY FUNCTION TEST MEASUREMENTS BEFORE SURGERY

Lung volumes

The mean values of VC, TLC, FRC, RV, and RV/TLC did not differ from the reference values. FRC/TLC was increased $(p<0.01)$ (table 1).

\section{Lung elasticity}

The mean values of lung recoil pressure (Pst) measured at $100 \%$ and $90 \%$ of total lung capacity were significantly increased: lung recoil measured at $100 \%$ TLC $\left(\mathrm{Pst}_{100}\right)$ reached $123 \%$ of the reference value $(\mathrm{p}<0.0005)$. Pst $_{60}$ did not differ from the reference value. The value of Cst/TLC was mildly decreased (91\% of predicted, $\mathrm{p}=0.051)$ (table 1$)$.

\section{Airway patency}

A significant decrease of sGaw to $72(18) \%$ of predicted value $(\mathrm{p}<0.0001)$ was found. Mean values of PEFR and $\mathrm{MEF}_{25} \mathrm{VC} / \mathrm{TLC}$, $\mathrm{MEF}_{50} \mathrm{VC} / \mathrm{TLC}$, and $\mathrm{MEF}_{60}$ TLC/TLC were normal (table 1).

\section{Frequency of abnormal lung function tests}

Abnormal lung function tests (that is, tests deviating by more than $2 \mathrm{SD}$ from the mean normal value) were found in 18 of the 26 patients $(69.2 \%)$ (table 2 ). Lung recoil pressure, indicating stiff lung, was significantly increased in 12 patients $(46.2 \%)$ and decreased in two $(7.7 \%)$, respectively. Maximum expiratory flow rates-indicating peripheral airway 
Table 1 Pulmonary funtion before and after surgery for atrial septal defect

\begin{tabular}{|c|c|c|c|c|c|c|c|c|}
\hline \multirow[b]{3}{*}{ Variable } & \multicolumn{3}{|c|}{ Before surgery $(n=26)$} & \multicolumn{3}{|c|}{ After surgery $(n=24)$} & \multirow{2}{*}{\multicolumn{2}{|c|}{$\begin{array}{l}\text { Postoperative v preoperative } \\
\text { values }\end{array}$}} \\
\hline & \multicolumn{2}{|c|}{$\%$ Predicted } & \multirow{2}{*}{$\begin{array}{l}p \text { value } v \\
\text { predicted }\end{array}$} & \multicolumn{2}{|c|}{$\%$ Predicted } & \multirow{2}{*}{$\begin{array}{l}p \text { value } v \\
\text { predicted }\end{array}$} & & \\
\hline & Mean & $S D$ & & Mean & $S D$ & & $\%$ Change & $p$ value \\
\hline $\mathrm{VC}(\mathrm{ml})$ & 96.9 & 13.8 & NS & 97.1 & 14.5 & NS & 0.2 & NS \\
\hline $\mathrm{FRC}(\mathrm{ml})$ & 103.3 & 14.2 & NS & 81.0 & 18.3 & $<0.05$ & -21.6 & $<0.0001$ \\
\hline TLC (ml) & 98.4 & 10.1 & NS & 95.4 & 12.4 & NS & -3.0 & NS \\
\hline $\mathrm{RV}(\mathrm{ml})$ & 104.6 & 17.6 & NS & 90.3 & 24.9 & NS & -13.7 & $<0.01$ \\
\hline RV/TLC (\%) & 107.5 & 19.2 & NS & 97.9 & 19.7 & NS & -8.9 & $<0.05$ \\
\hline FRC/TLC (\%) & 105.9 & 9.1 & $<0.01$ & 94.2 & 10.5 & $<0.005$ & -11.0 & $<0.0001$ \\
\hline $\mathrm{Cst} / \mathrm{TLC}\left(\mathrm{ml} . \mathrm{cm} \mathrm{H}_{2} \mathrm{O}^{-1} \cdot \mathrm{l}^{-1}\right)$ & 90.9 & 23.0 & NS & 87.6 & 20.5 & NS & -3.6 & NS \\
\hline Pst $100 \%$ TLC $\left(\mathrm{cm} \mathrm{H}_{2} \mathrm{O}\right)$ & 123.3 & 25.4 & $<0.0005$ & 131.8 & 25.2 & $<0.00001$ & 6.8 & NS \\
\hline Pst $90 \%$ TLC $\left(\mathrm{cm} \mathrm{H}_{2} \mathrm{O}\right)$ & 109.8 & 22.8 & $<0.05$ & 116.6 & 20.5 & $<0.0005$ & 6.2 & NS \\
\hline Pst $60 \%$ TLC $\left(\mathrm{cm} \mathrm{H}_{2} \mathrm{O}\right)$ & 110.7 & 38.1 & NS & 127.2 & 36.3 & $<0.0005$ & 14.9 & NS \\
\hline $\mathrm{sGaw}\left(\mathrm{cm} \mathrm{H}_{2} \mathrm{O}^{-1} \cdot \mathrm{s}^{-1}\right)$ & 72.0 & 17.9 & $<0.0001$ & 101.3 & 30.4 & NS & 40.7 & $<0.0005$ \\
\hline $\operatorname{PEFR}\left(1 . \mathrm{s}^{-1}\right)^{2}$ & 95.0 & 17.1 & NS & 102.7 & 17.7 & NS & 8.1 & $<0.05$ \\
\hline MEF $25 \%$ VC/TLC $\left(1 . \mathrm{s}^{-1} \cdot 1^{-1}\right)$ & 102.5 & 28.9 & NS & 103.7 & 36.3 & NS & 1.2 & NS \\
\hline MEF50\%VC/TLC $1\left(1 . \mathrm{s}^{-1} .1^{-1}\right)$ & 109.3 & 20.4 & NS & 109.6 & 23.4 & NS & 0.3 & NS \\
\hline MEF60\%TLC/TLC $\left(1 . \mathrm{s}^{-1} \cdot 1^{-1}\right)$ & 105.4 & 25.0 & NS & 113.7 & 27.6 & 0.05 & 7.9 & NS \\
\hline
\end{tabular}

Cst/TLC, static compliance corrected for total lung capacity; FRC, functional residual capacity; MEF, maximum expiratory flow (corrected for total lung capacity); PEFR, peak expiratory flow rate; Pst, static lung recoil pressure; Raw, airway flow resistance; RV residual volume; sGaw, specific airway conductance; TLC, total lung capacity; VC, vital capacity.

obstruction-were significantly reduced in four patients (15.4\%). PEFR and sGaw-indicating central airway obstruction-were also significantly reduced in four patients $(15.4 \%)$. Total lung capacity was significantly decreased in two patients $(7.7 \%)$. Values of FRC/TLC and RV/TLC-indicating lung hyperinflationwere significantly increased in five patients $(19.2 \%)$.

PULMONARY FUNCTION TEST MEASUREMENTS AFTER SURGERY

Lung volumes

The mean values of VC, TLC, RV, and RV/TLC did not differ from the reference values (table 1 ). The mean values of FRC and FRC/TLC were decreased $(p<0.05$ and $\mathrm{p}<0.005$, respectively).

\section{Lung elasticity}

The mean lung recoil pressure values measured at $100 \%, 90 \%$, and $60 \%$ of TLC were increased, reaching $132 \%, 117 \%$, and $127 \%$ of predicted $(\mathrm{p}<0.00001, \mathrm{p}<0.0005$, and $\mathrm{p}<0.0005$, respectively) (table 1 ). The Cst/ TLC value remained normal.

\section{Airway patency}

The mean values of sGaw, PEFR, $\mathrm{MEF}_{25} \mathrm{VC} /$ TLC, and $\mathrm{MEF}_{50} \mathrm{VC} / \mathrm{TLC}$ did not differ from the reference value (table 1 ). The mean value of $\mathrm{MEF}_{60} \mathrm{TLC} / \mathrm{TLC}$ was higher than the reference values $(114 \%$ of predicted, $\mathrm{p}<0.05)$.

Frequency of abnormal lung function tests Abnormal lung function tests were found in 12 of the 24 patients tested $(50.0 \%)$ (table 2).

Table 2 Frequency of abnormal lung function before and after surgery for atrial septal defect

\begin{tabular}{|c|c|c|c|c|c|}
\hline & \multicolumn{2}{|c|}{ Before $(n=26)$} & \multicolumn{2}{|c|}{ After $(n=24)$} & \multirow[b]{2}{*}{$p$} \\
\hline & $n$ & $\%$ & $n$ & $\%$ & \\
\hline Lung volume restriction & 2 & 7.7 & 3 & 8.3 & NS \\
\hline Hyperinflation & 5 & 19.2 & 1 & 4.2 & NS \\
\hline Stiff lung & 12 & 46.2 & 9 & 37.5 & NS \\
\hline Emphysematous lung & 2 & 7.7 & 1 & 4.2 & NS \\
\hline Airway obstruction & & & & & NS \\
\hline Central & 4 & 15.4 & 0 & 0 & $<0.05$ \\
\hline Peripheral & 4 & 15.4 & 4 & 16.7 & NS \\
\hline Total & 18 & 69.2 & 12 & 50.0 & NS \\
\hline
\end{tabular}

Lung recoil pressure was increased in nine patients $(37.5 \%)$ and decreased in one $(4.2 \%)$. Maximum expiratory flow rates were reduced in four patients $(16.7 \%)$. No decreased specific airway conductance or peak expiratory flow rates were found. Total lung capacity was significantly decreased in three patients $(8.3 \%)$. The FRC/TLC and RV/TLC ratios were increased in only one patient $(4.2 \%)$.

COMPARISON OF PREOPERATIVE AND POSTOPERATIVE PULMONARY FUNCTION TEST DATA

The overall frequency of abnormal preoperative and postoperative pulmonary function tests $(18 / 26(69.2 \%) v 12 / 24(50.0 \%))$ did not differ significantly (table 2$)$.

\section{Lung volumes}

Values of FRC, RV, and FRC/TLC and RV/TLC ratios decreased significantly $(\mathrm{p}<0.0001, \quad \mathrm{p}<0.01, \quad \mathrm{p}<0.0001, \quad$ and $\mathrm{p}<0.05$, respectively). There was a mild decrease in TLC with no change in vital capacity (table 1).

Lung elasticity

No significant changes in lung recoil or static lung compliance were found (table 1).

Airway patency

A significant increase in sGaw $(\mathrm{p}<0.0005)$ and PEFR $(p<0.05)$ was found. Values of $\mathrm{MEF} / \mathrm{TLC}$ remained unchanged in all cases (table 1).

RELATIONS BETWEEN PREOPERATIVE PULMONARY HAEMODYNAMICS, PERIOPERATIVE EVENTS, AND LUNG FUNCTION

Age at surgery

There was a positive linear correlation of postoperatively measured TLC and VC with age at surgery $(r=0.461, \mathrm{p}<0.03$ and $r=0.648$, $\mathrm{p}<0.002$, respectively). There was a positive linear correlation of postoperative $\mathrm{MEF}_{60} \mathrm{TLC} /$ TLC and PEFR with age at surgery $(r=0.450$, $\mathrm{p}<0.03$ and $r=0.514, \mathrm{p}<0.02$, respectively). Postoperative elastic recoil at $90 \%$ TLC correlated inversely with age at surgery $(r=-0.575, \mathrm{p}<0.01)$. 
Magnitude of left to right shunt

No correlation between the preoperative left to right shunt and preoperative or postoperative pulmonary function test data was found.

Perioperative events

There was no correlation between duration of cardiopulmonary bypass, aortic cross clamp, or ventilation and preoperative or postoperative pulmonary function test data.

\section{Pulmonary function tests}

There was a negative correlation between postoperative elastic recoil measured at $60 \%$ TLC and RV/TLC $(r=-0.489, \mathrm{p}<0.05)$, and a negative correlation between elastic recoil measured at $100 \%$ TLC and FRC/TLC $(r=-0.478, \mathrm{p}<0.03)$.

\section{Discussion}

In our previous paper ${ }^{13}$ we found pulmonary function test abnormalities in 35 of 74 patients $(47 \%)$ tested five years after heart surgery for ASD. These findings were surprising in view of the excellent clinical outcome of the surgery at the time of testing. In the present series - which was done with completely different subjects than in our previous study-the overall frequency of pulmonary function test abnormalities after surgery lessened slightly, from $69 \%$ to $50 \%$ of patients. Similarly, only discrete postoperative changes in dynamic lung volumes have been documented elsewhere. ${ }^{3}$

A reduction in TLC (a measure of lung size) was found both preoperatively and after surgery in only $7.7 \%$ and $8.3 \%$ of patients, respectively. This is in line with their excellent clinical condition. The most frequent abnormality we found in the present study was increased lung stiffness. Non-uniform changes in lung elasticity found in previous studies are not surprising, because (except in those by DeTroyer et al and Šulc et $a l^{213}$ ) dynamic lung compliance was usually the only indicator considered. Increased lung recoil pressure measured at different levels of TLC $^{21322}$ is a more sensitive index for detecting abnormalities of lung elasticity. An even more pronounced increase in lung stiffness (assessed by the same method) was found long term in patients after surgery for simple transposition of the great arteries ${ }^{23}$ and ventricular septal defect. ${ }^{24}$ Changes in the elastic properties of the lungs before surgery could be caused by increased pulmonary blood flow and volume $\mathrm{e}^{25}$ and engorgement of the capillary network. ${ }^{626}$ Persistence of stiff lung indices in other types of congenital heart defect with high pulmonary blood flow can result from vascular changes 27 leading to progressive remodelling of the lung parenchyma, even with fibrotic changes. ${ }^{122}$ The different responses of fetal compared with adult vascular smooth muscle cells to high pulmonary blood flow and pressure ${ }^{27}$ could also influence the outcome. Long term changes in pulmonary blood flow could affect the fragile balance between hypercompliant perivascular and hypocompliant peribronchial parenchyma, ${ }^{29}$ and might lead to reorganisation of related pulmonary parenchymal structures. ${ }^{30}$
Any form of adaptation of the lung parenchyma and pulmonary vasculature to a new haemodynamic status should also be considered.

The surgical procedure itself is unlikely to contribute substantially to increased lung stiffness postoperatively. The patients were exposed by central sternotomy to a very short period of cardiopulmonary bypass and ventilation, avoiding all but the most trivial damage to the lungs. Under such conditions, only short term changes caused by a temporary increase of extravascular lung water and relative lymphatic insufficiency have been found. ${ }^{31}$ There are confirmatory reports on the absence of changes in the static compliance of the respiratory system during cardiopulmonary bypass in children operated on for ASD. ${ }^{32}$

It is difficult to draw any conclusion about possible anatomical abnormalities of the lung parenchyma causing stiff lungs because no open lung or transbronchial biopsies were available in our patients. We might hypothesise that the normal growth of the elastic and collagen tissue during the fetal and perinatal period may be altered by abnormal pulmonary haemodynamics influencing lung development up to the time of heart surgery. ${ }^{230}$

Hyperinflation, indicated by the increased ratios of FRC/TLC and RV/TLC, was seen preoperatively in $19 \%$ of our patients, compared with $4 \%$ postoperatively. Our postoperative data are similar to those of adults with uncorrected atrial septal defects. ${ }^{25}{ }^{6}$ Generally, a higher preoperative pulmonary blood flow might contribute to hyperinflation. The postoperative reduction in hyperinflation was inversely correlated with the slight increase in the frequency of stiff lung. Therefore we might hypothesise a beneficial effect of a stiffer lung, which could result in a lesser degree of hyperinflation. Previous findings of a high frequency of stiff lung (24/74 patients $(32 \%))$ and low incidence of hyperinflation $(<5 \%$ of the patients) in another group of patients studied more than five years after correction of $\mathrm{ASD}^{13}$ tend to confirm this suggestion.

Similarly, a reduced maximum expiratory flow rate at lower levels of vital capacity, indicating peripheral (smaller) airway obstruction, was found before as well as after surgery in only $15 \%$ and $17 \%$ of our patients, respectively. This may be caused by the harmful impact of increased pulmonary blood flow and volume on small airways. However, the mean values of these indices were "supranormal" (reaching $103-109 \%$ and $104-113 \%$ of predicted, respectively), implying on average a normal peripheral airway patency in the group as a whole. An observation of preoperatively decreased airway conductance, indicating obstruction of the central (larger) airways, in 15\% of our patients could be related to abnormal haemodynamics and repeated preoperative infections. ${ }^{33}$ Peripheral airway obstruction was detected preoperatively in only one of the three patients with a history of repeated bronchitis. In none of them, however, did surgery related events lead to an increase in airflow limitation. Moreover, no correlation between the duration 
of ventilation (up to seven hours) and airway patency indices was found which might suggest a deleterious effect of tracheal intubation itself. The only deterioration in postoperative pulmonary function tests (development of peripheral airway obstruction and hyperinflation) was found in a boy who was reintubated and ventilated for a short period for respiratory insufficiency.

A negative correlation between age at surgery and postoperative lung recoil, and a positive correlation between age at surgery and postoperative lung volume show that earlier heart surgery was not beneficial either for postoperative lung size or lung elasticity. The findings of a positive correlation between age at surgery and postoperative airway patency index may also indicate that the earlier the surgery, the "worse" the airway patency. There have been similar findings in patients after atrial correction for simple transposition. ${ }^{22}$ We hypothesise that even a successful repair reversing all haemodynamic effects could not reverse the harmful impact of abnormal pulmonary haemodynamics on the developing lung.

These findings have, however, to be interpreted cautiously because our group represents one of the first containing patients operated on as late as a mean age of 11.8 years. At present, patients are scheduled for surgery for ASD at the age of 1 to 4 years. It may thus be the case that those patients who have remained unoperated or even undiagnosed until an older age were those with less significant impairment of both cardiac and pulmonary function.

\section{CONCLUSIONS}

Surprisingly, the surgical repair of ASD did not result in substantial improvement in postoperative pulmonary function tests. When comparing preoperative with postoperative data, we found a small decrease in the overall frequency of pulmonary function test abnormalities, with little reduction in the frequency of stiff lung or indices of lung hyperinflation. The surgical procedure itself, and the perioperative and early postoperative factors, did not produce any marked change in the frequency and severity of pulmonary function test abnormalities. This has implications for patients receiving surgery for more severe forms of congenital heart disease, where the overall incidence of abnormal postoperative pulmonary function test results is substantially higher ${ }^{22}{ }^{34}$ (using similar surgical procedures). Therefore this rather prominent degree of lung dysfunction is probably caused by events unrelated to perioperative or postoperative factors.

We thank Marie Špírová and Květa Kozerová for their technical assistance during the study. Supported by grants from the Czech Ministry of Health, Nos 2050-3, 3935-3, and 3919-3.

1 Bedell GN, Adams RV. Pulmonary diffusing capacity during rest and exercise. A study of normal persons and person with atrial septal defect, pregnancy and pulmonary disease. $\mathcal{f}$ Clin Invest 1962;41:1908-14

2 DeTroyer A, Yernault J-C, Engkert M. Mechanics of breathing in patients with atrial septal defect. Am Rev Respir Dis 1977;15:413-21.
3 Schofield PM, Barber PV, Kingston T. Preoperative and postoperative pulmonary function tests in patients with atrial septal defect and their relation to pulmonary artery pressure and pulmonary:systemic flow ratio. Br Heart 7 pressure and pulmo

4 Turino GM. Pulmonary distensibility in mitral stenosis and congenital heart disease. $\mathcal{F}$ Clin Invest 1956;35:740.

5 Yoshioka T, Kunieda T, Naito M, et al. Effects of pulmonary hemodynamics on lung function in adult patients with atrial septal defect. Fpn Circ $\mathcal{F}$ 1985;49:960-6.

6 Wood TF, McLeod P, Anthonisen NR, et al. Mechanics of breathing in mitral stenosis. Am Rev Respir Dis 1971;104: $52-60$.

7 Davies H, Gazetopoulos N. Lung function in patients with left-to-right shunts. Br Heart f 1967;29:317-26.

8 Cowen ME, Jeffrey RR, Drakeley MJ, et al. The results of surgery for atrial septal defect in patients aged fifty years and over. Eur Heart f 1990;11:29-34.

9 Ayres SM, Kozam RL, Lukas DS. Mechanics and work of breathing in atrial septal defect. Circulation 1960;22:71819.

10 Verstraeten JM, Verstraeten J, Pannier R. La compliance pulmonaire chez les sujets adultes présentant une cardiopathie congénitale. Arch Mal Coeur 1964;57:1409-20.

11 Girardet JP, Gaultier C, Boule M, et al. Perturbations fonctionnelles respiratoires chez les enfants porteurs de cardiopathies avec shunt gauche-droite. Arch Mal Coeur 1981;74: $1147-55$.

12 Wallgren G, Geubelle F, Koch G. Studies of the mechanics of breathing in children with congenital heart lesions. Acta Paediatr 1960;49:415-25.

13 Sulc J, Samánek M, Zapletal A. Lung function in atrial septal defect after heart surgery. Int $\mathcal{F}$ Cardiol 1992;37:15-21.

14 Griffin AJ, Ferrara JD, Lax JO, et al. Pulmonary compliance - an index of cardiovascular status in infancy. Am f Dis Child 1972;123:89-95.

15 Bucci G, Cook CD. Studies of respiratory physiology in children. VI. Lung diffusing capacity, diffusing capacity of the pulmonary membrane and pulmonary capillary blood volume in congenital heart disease. $\mathcal{F}$ Clin Invest 1961;40: 1431-41

16 Bancalari E, Jesse MJ, Gelband $\mathrm{H}$, et al. Lung mechanics in congenital heart disease with increased and decreased pulmonary blood flow. F Pediatr 1977;90:192-5.

17 Havelová L. Pathologic lung function in children and adolescents with congenital heart defects. Pediatr Cardiol 1996;17:314-15.

18 Mcllroy MB, Apthorp GH. Pulmonary function in pulmonary hypertension. Br Heart f 1958;20:397-402.

19 Davies H, Williams J, Wood P. Lung stiffness in states of abnormal pulmonary blood flow and pressure. Br Heart $\mathcal{F}$ 1962;24:129-38.

20 Larmi TKI, Appelquist R. The influence of cardiac surgery on the mechanical properties of the lungs. Scand $\mathcal{F}$ Clin Lab Invest 1961;13:174-9.

21 Haughton V. Changes in pulmonary compliance in patients undergoing cardiac surgery. Dis Chest 1968;53:617-28.

22 Zapletal A, Samánek M, Paul T. Lung function in children and adolescents, 1st ed. Basel: Karger, 1987:10-45.

23 Šamánek M, Sulc J, Zapletal A. Lung function in simple complete transposition after intracardiac repair. Int $\mathcal{F}$ Cardiol 1989;24:13-17.

24 Šulc J, Samánek M, Zapletal A, et al. Lung function in VSD patients after corrective heart surgery. Pediatr Cardiol 1996; $17: 1-6$

25 Englert M. Pulmonary capillary blood volume in conditions with high pulmonary blood flow: pneumonectomy and congenital cardiac malformations with left to right shunt. In: Daum S, Widimský J, eds. Progress in respiratory research, In: Daum S, Wasel: Karger, 1970:338-45.

26 Giannelli S, Ayres SM, Buehler ME. Effect of pulmonary blood flow upon lung mechanics. $\mathcal{F}$ Clin Invest 1967;46: 1625-42.

27 Rudolph AM. Comment: Pulmonary hypertension: it all begins with EVE (endogenous vascular elastase). Isr f Med Sci 1996;32:809-10

28 Rosengart R, Fishbein M, Emmanoulides GC. Progressive pulmonary vascular disease after surgical correction (Mustard procedure) of transposition of great arteries with intact ventricular septum. Am F Cardiol 1975;35:107-11.

29 Oldmixon EH, Butler JP, Hoppin FG. Peristructural parenchymal heterogeneity [abstract]. Am F Respir Crit Care Med 1997; 155:A743.

30 Rabinovitch M, Keane JF, Norwood WI, et al. Vascular structure in lung tissue obtained at biopsy correlated with pulmonary hemodynamic findings after repair of congenital heart defects. Circulation 1984;69:655-67.

31 Vincent RN, Lang P, Elixson EM, et al. Extravascular lung water in children immediately after operative closure of either isolated atrial septal defect or ventricular septal either isolated atrial septal defect
defect. Am 7 Cardiol 1985;56:536-9.

32 Shulman DL, Burrows FA, Poppe DJ, et al. Perioperative respiratory compliance in children undergoing repair of atrial septal defects. Can f Anaesth 1991;38:292-7.

33 Corno A, Giamberti A, Giannico S, et al. Airway obstruction associated with congenital heart disease in infancy. $\mathcal{F}$ Thorac Cardiovasc Surg 1990;99:1091-8.

34 Zapletal A, Samánek M, Hruda J, et al. Lung function in children and adolescents with tetralogy of Fallot after intracardiac repair. Pediatr Pulmonol 1993;16:23-30. 